\title{
An Introduction to the Development and Regulation of Agricultural Insurance in China
}

\section{Zhou Yanli}

China Insurance Regulatory Commission, No. 15 Jinrong Dajie, Xicheng District, Beijing, People's Republic of China.

The importance of agriculture in a country with 1.3 billion people is self-evident. Agricultural insurance, however, did not emerge in China until the 1930s. Having gone through twists and turns, agricultural insurance is now widely recognised as an important means of protection for production and for the life of people in rural areas. Under the guidance and with the support of the government at all levels, pilot projects of agricultural insurance are being carried out. The China Insurance Regulatory Commission is strengthening its supervision of agricultural business and exploring a set of regulations for this sector. As a result, the market is growing quickly; the market structure has become more diversified and more products are available. In the pilot efforts to find a good model for agricultural insurance in China, some successful experiments have been made. Policy support is found to be a necessity in a sustainable agricultural insurance system for China. Local differences should receive appropriate attention and innovation should be encouraged to create a practical agricultural system that satisfies local needs in a large country like China.

The Geneva Papers (2009) 34, 78-84. doi:10.1057/gpp.2008.39

Keywords: agricultural insurance; China

\section{Introduction}

As a large country with 1.3 billion people, China has witnessed the fundamental role of agriculture in its national economy and social stability. In order to support a sustained, rapid and sound development of its economy and society, China has been striving to provide sufficient protection for the development of agriculture and the rural economy by enhancing the role of agricultural insurance since the late 1970s.

\section{The evolution of agricultural insurance in China}

Agricultural insurance in China has experienced a twisted path of development since its first appearance more than seven decades ago. Its evolution can be roughly divided into three stages.

\section{The initial stage}

In the 1930s and 1940s, some regions in a few provinces started to provide agricultural insurance. A government-funded specialised agricultural insurance company, China 
Agricultural Insurance Company Limited, was also established. But this attempt was short-lived due to the high risk of agricultural insurance, weak economy and lack of policy support at that time. After the establishment of the People's Republic of China in 1949, based on the agricultural insurance model of the former Soviet Union, the China Agricultural Insurance Company (CAIC) started a trial agricultural insurance. In the 1950s, the People's Insurance Company of China (the original PICC) also started its agricultural insurance. But all these insurances were suspended in 1953 as the government had to use all the financial means, which were scarce at that time, to ensure the production of agriculture.

\section{The exploration stage}

These insurances were resumed and developed after the adoption of the reform and opening-up policy in the late 1970s. In 1982, PICC resumed its agricultural insurance. The government did not provide policy support, and the losses in agriculture insurance were made up by other lines of business within the company. In 1986, the Agriculture \& Animal Husbandry Insurance Company under the Xinjiang Production and Construction Corp (currently known as the China United Property Insurance Company) was set up. Its main business was agricultural insurance. During this period, agricultural insurance was provided on a full commercial basis but suffered sustained underwriting losses. For example, between 1982 and 1993, the agricultural premium income of PICC totalled RMB 2.967 billion Yuan while its total amount of payout reached RMB 2.877 billion Yuan. Taking 15 per cent of the premium as operating expenses, the company suffered a loss of RMB 355 million Yuan. Because of the lack of government support, after reaching a temporary peak of RMB 817 million Yuan in 1992, the market size of agricultural insurance in China shrank every year with the number of products decreasing from more than 60 to around 30 .

\section{The breakthrough}

Since 2002, the Chinese government increased its financial support to agriculture and made agricultural insurance a part of its overall development plan for a new socialist countryside. In 2004, the CPC Central Committee and the State Council wrote in the Opinions on Some Policies of Increasing Farmers' Income: "to accelerate the establishment of a policy mechanism of agricultural insurance, and to choose a number of products and regions for pilot projects. Eligible places may provide certain premium subsidy for farmers who purchase planting and livestock breeding insurance". ${ }^{1}$ With this impetus, the China Insurance Regulatory Commission (CIRC) initiated government promoted agricultural insurance pilot projects in Shanghai, Hei Longjiang, Ji Lin, Xin Jiang, Jiang Su, Si Chuan and Hu Nan. Government at all levels adopted policies to support agricultural insurance thereafter. With steady progress of the pilot projects and continuously improving regulation, agricultural insurance is gradually entering a stage of rapid and sound development.

\footnotetext{
${ }^{1}$ Opinions on Some Policies of Increasing Farmers' Income (2004, p. 4).
} 


\section{China's perspectives on the development of agricultural insurance}

The importance of developing agricultural insurance is recognised by the Chinese government mainly as follows.

Agricultural insurance is a central component in the support and protection system for agriculture

China suffers frequently from natural disasters. As in other parts of the world, agriculture is especially vulnerable to natural disasters. At the beginning of 2008, several provinces in southern China were hit by an exceptionally severe disaster of low temperatures and heavy snowstorms, causing great damage and losses to the agriculture and farmers. This disaster, together with the Sichuan earthquake in May 2008 and many other disasters in the past, demonstrates the need for agricultural insurance as a means of risk transfer for agriculture. It is necessary to establish an agricultural insurance system to protect farmers from financial losses and to safeguard agricultural production for the sake of national food security.

Agricultural insurance is an important means to develop modern agriculture

Modern agriculture differs from traditional agriculture in that it faces not only more natural disasters, but also increasing market and technological risks. As a result of a shortage of rice and other agricultural products in the international market in 2008, social instability and turmoil have occurred in some countries. With the increase of other risks such as avian flu, mad cow disease and the abusive use of biochemical products, people are becoming more and more concerned with the quality and safety of agricultural products. Strengthening risk management in all areas of agriculture such as production, disaster-prevention, sales, etc., will help ensure the correct use and promotion of agricultural technology, stabilise the market supply of agricultural products and promote the industrialisation of agriculture. Good risk management will be conducive to build a sound, advanced and open modern agriculture in China.

\section{Agricultural insurance improves the financial system in rural areas}

At present, developing micro-insurance and micro-credit loans so as to better serve agriculture, rural areas and farmers has become an important task of the financial services sector in China. As a weak link in the Chinese financial system that faces many problems and contradictions, current rural finance can hardly meet farmers' multi-faceted financial needs effectively. Developing agricultural insurance and linking it with micro-credit can stabilise the risk expectation of investment in agriculture, expand financing channels for farmers and provide powerful financial support for agricultural development. 


\section{Three characteristics of current agricultural insurance in China}

\section{Rapid growth in market scale}

In 2007, premium income and payout of agricultural insurance throughout China totalled RMB 5.333 billion Yuan and RMB 2.975 billion Yuan, respectively, up 529 and 403 per cent over that of the previous year, both hitting a record high. In the same year, about 28.88 million fertile sows had insurance coverage, accounting for 60 per cent of the country's total. Area of rice and other major agricultural products covered by government promoted agricultural insurance reached 140 million mu, ${ }^{2}$ about 70 per cent of the planted area in the pilot regions.

\section{Gradual market entry of additional specialised players}

China has granted licences to three specialised agricultural insurance companies since 2004, namely Anxin Agricultural Insurance Company, Anhua Agricultural Insurance Company and Sunlight Mutual Insurance Company. These companies are mainly government-funded joint stock companies. With the entrance of these companies, farmers can purchase agricultural insurance policies from both specialised insurers such as those mentioned above and general insurance companies such as PICC. The policies can be commercial policies or government-subsidised policies.

\section{Improving product diversity and availability}

Insurance companies have strengthened the innovation of agricultural products according to the actual needs of different regions. Besides insurance for major grain crops, special insurance products for trees, colza and tobacco, as well as agricultural products price insurance and food quality guaranty insurance have also been developed. Currently, there are more than 160 agricultural insurance products covering almost all fields of the planting and livestock breeding industry. Meanwhile, agricultural insurance has covered all provinces (including regions and municipalities) in China.

\section{Three aspects of policy support to agricultural insurance in China}

The Chinese government places high priority on the development of agriculture and rural areas, and the protection of farmers' income. As an important means to serve this end, agricultural insurance has received great attention from the government. The respective external environment has been improved remarkably, which greatly facilitates the development of agricultural insurance in China.

\footnotetext{
${ }^{2} \mathrm{Mu}$ is a Chinese measure of area $=666 \mathrm{~m}^{2}$.
} 


\section{Guidance from the central government}

In 2004, the No. 1 central document put forward specific requirements to develop government promoted agricultural insurance. In 2006, the State Council issued another important document, Some Opinions of the State Council on the Reform and Development of the Insurance Industry, which required the insurance industry to promote pilot projects and to develop agricultural insurance of various forms and distribution channels. In addition, the State Council pointed out clearly in 2007 that an agricultural insurance system should be established and improved according to the principles of government guidance, policy support, market operation and voluntary participation. In March 2008, the State Council held a national television and telephone conference on agriculture and food production, which further strengthened policy support to agricultural insurance and clearly defined agricultural insurance as one of the 10 major policies to protect agriculture and food production.

\section{Cooperation of local government}

In their effort to implement the central government plan and to develop local agricultural insurance, government bodies at local levels have established various models of agricultural insurance. There is the joint model in which the government and insurance companies assume the risk together, the agency model in which the government assumes the risk while insurance companies operate as the agent and the insurer model in which insurance companies operate with policy support. In the process of promoting agricultural insurance development, local governments strengthened their guidance and leadership. At present, more than 20 provinces (including regions and municipalities) in China have promulgated specific measures to promote local agricultural insurance development. Some regions make use of the influence of leading enterprises, large farms and agricultural cooperative organisations to encourage farmers to purchase insurance and link government promoted agricultural insurance with rural micro-credit loans, forest rights mortgage loans, disaster assistance and favourable policies from the government.

\section{Financial subsidies at all levels}

At the beginning of 2007, the Ministry of Agriculture and the CIRC drew up the Pilot Proposal of Government Promoted Agricultural Insurance, which put forward the target, principle and development plan of government promoted agricultural insurance, and formulated the specific scheme of central financial subsidy. Based on this proposal, the Ministry of Finance allocated, for the first time, RMB 2.15 billion from the budget for the basic scheme of premium subsidy pilot projects of planting and livestock breeding insurance and sow insurance, defining the responsibility of premium allocation in which the central and provincial government each provide a subsidy of 25 per cent of the premium and the remaining 50 per cent is jointly assumed by the farmers, leading enterprises and departments of finance at province, city and county levels. In 2008, government bodies at all levels have further strengthened their support to agricultural insurance. 


\section{The role of the CIRC in the development of agricultural insurance}

As the regulator and governing body of the commercial insurance industry in China, the CIRC was established in 1998 and plays a critical role in the development of China's insurance industry. In recent years, the CIRC has adopted the development of agricultural insurance as a priority, promoting its development in three aspects.

\section{Communication and coordination with relevant government departments}

Because of the sheer size of the country and frequent occurrence of natural disasters, the private insurance sector in China cannot assume the agricultural risks alone without support from the government. Therefore, good communication and coordination among different ministries and between ministries and local governments are critical to the success of the pilot projects and the development of the agricultural insurance system. The CIRC has done a lot in improving the communication and coordination among relevant ministries and with local governments. For example, the CIRC has formed a joint research team with the General Office of the State Council and the Ministry of Agriculture, and has carried out many specific studies into the expansion of the agricultural insurance pilot work. At the same time, the CIRC continues its efforts to try to win policy support from the State Council and relevant government bodies to issue documents to advance agricultural insurance pilot work.

\section{Organisation and guidance}

The CIRC encourages the market access of specialised agricultural insurance companies. It draws up pilot schemes for agricultural insurance, asking insurance companies to tailor their products to local realities in different rural areas and to satisfy farmers' needs to the greatest extent.

\section{Regulation and supervision}

To protect the interests of farmers, the CIRC regulates premium rates of agricultural insurance and strictly supervises claims settlement of agricultural insurance business. In addition, in order to effectively control the risk in this business, the CIRC makes requirements on insurance companies regarding their operating cost control and independent accounting for agricultural insurance. The CIRC also plans to establish and improve relevant statistical and reserve systems for agricultural insurance and timely follow up the development of agricultural insurance in various regions, in order to provide data support for the further improvement of agricultural insurance and to ensure its sustainable development.

\section{China's experiences in developing agricultural insurance}

In its efforts to explore a model of agricultural insurance development, China has had some valuable experiences. Based on these experiences, China is going to further advance agriculture insurance in a sound and rapid way. 
Policy support is a necessity in the development of agricultural insurance

Because of various reasons, farmers and grass-root organisations in rural areas are not very aware of the need for insurance. On the other hand, insurance companies are not active enough in providing agricultural insurance because of the high risks in this line of business. Therefore, it is of great necessity for the government to play a role in expanding the coverage of agricultural insurance by improving farmers' insurance awareness, providing financial subsidies and encouraging insurance companies to expand in this area.

\section{Enough attention must be paid to local realities}

There is still a wide gap between the conditions of agriculture, rural areas and farmers in China and in other countries. Within the vast territory of China, there are a great variety of crops and livestock, different agricultural structures as well as different levels of agricultural and social-economic development. Because of these differences, the establishment of an agricultural insurance system should be carried out step by step based on the experiences from the pilot projects. The pilot projects themselves should be practical and feasible. Experiences of the pilot projects should be applied and spread gradually through exploration.

\section{Innovation should be encouraged}

Agricultural insurance is a new business in China with no successful precedents to learn from. Models of other countries, however successful as they have been, may not work for China when simply copied to this country. Therefore, innovation cannot be over-emphasised when it comes to each aspect of a practical and sustainable agricultural insurance system - operation, product development, service delivery, regulation and supervision.

\section{References}

Ministry of Agriculture and CIRC, People's Republic of China (2007) Pilot Proposal of Government Promoted Agricultural Insurance.

The State Council of People's Republic of China (2004) Opinions on Some Policies of Increasing Farmers' Income.

The State Council of People's Republic of China (2007) Some Opinions of the State Council on the Reform and Development of the Insurance Industry.

\section{About the author}

Zhou Yanli was born in June 1956. He is the Deputy Chairman of CIRC. He has also been an Assistant Chairman of CIRC and Director General of Shanghai branch, CIRC. 